\title{
Immediate positive effects of physical therapy on gait disturbance in patients with parkinson's disease
}

\author{
Naoki Wada ${ }^{1 *}$, Makoto Sohmiya ${ }^{1}$, Masayuki Tazawa', Yoko Ibe ${ }^{1}$, Koichi Okamoto² and Kenji Shirakura \\ *Correspondence: nwada@gunma-u.ac.jp \\ CrossMark \\ $\leftarrow$ Click for updates \\ 'Department of Rehabilitation Medicine, Gunma University Graduate School of Medicine, Japan. \\ 2Department of Neurology, Geriatrics Research Institute and Hospital, Japan.
}

\begin{abstract}
Background: Gait disturbance is major disturbance of Parkinson's disease (PD). Although continuous physical therapy (PT) has been demonstrated to improve gait disturbance and prevent falls among PD patients, few studies have reported on the immediate effect of PT. The aim of this study is to investigate the immediate effects of PT on gait parameters and joint kinematics in patients with PD.

Methods: Forty patients with idiopathic PD (Hoehn and Yahr stage 3-4) participated to the study. Participants were allocated to two groups: the intervention group participated in asingle 30-min PT session consisting of stretching exercises, strengthening exercises, balance training and gait training; the control group rested for 30-min. Gait parameters and range of angular motion of the joints were assessed using a three-dimensional motion analysis system in all patients before and after the session. Differences in the mean scores before and after intervention were examined.

Results: Walking speed and step length were significantly improved after PT. The range of angular motion of the shoulder, elbow and knee joint were expanded after PT. There was a significant interaction effect for improved walking speed, step length, trunk forward inclination and range of angular motion of the joints between the two groups and before and after PT sessions.

Conclusions: PT confers immediate positive effects on gait parameters. Gait disturbance, the main disorder of PD, is expected to be improved by single session of PT.
\end{abstract}

Keywords: Parkinson's disease, physical therapy, gait disturbance, motion analysis

\section{Introduction}

Parkinson's disease (PD) is a progressive neurological disorder that causesloss of functional abilities in areas such as gait. Gait disturbancein PD is characterized by reduced walking speed, shortened step length, freezing, pulsion, anteversion of posture and reduced arm swing [1-3]. Reduced walking speed in PD appears to result from a deficit in producing an appropriate steplength, rather than in cadence (step frequency) [4], and it is this particular disturbance in gait that tends to lead to a fear of falls among PD patients. Indeed, previous studies have reported that $38-54 \%$ of PD patients had experienced one or more falls in the previous 3 months $[5,6]$. Some studies have suggested that the impairment in the ability to regulate step-to-step variability might be responsible for falls in patients with $\mathrm{PD}[7,8]$. Although physical therapy (PT) alongside the administration of antiparkinsonian drugs has been demonstrated to improve gait disturbance and prevent falls among PD patients, few studies have reported on the efficacy of PT alone [9].

As suggested by Morris et al., [10], there are two major rehabilitation approaches for PD. Motor learning and motor control training is based on compensatory strategies to bypass the defective basal ganglia, teaching PD patients to move easily and safely. In contrast, musculoskeletal exercises aim to improve the strength, range of motion, endurance and aerobic capacity of PD patients. A meta-analysis of studies investigating the effects of PT in PD showed significantly improved scores in relation to activities of daily living (ADLs) and the Unified Parkinson's Disease Rating Scale (UPDRS), as well as significantly improved step length and walking speed [11].

Thus far, there has been little attempt to evaluate the gait of PD patients using quantitative biomechanical analysis. Some studies have measured the effect of surgical treatment or L-dopa 
Wada et al. Physical Therapy and Rehabilitation 2014,

medication on gait using three dimensional (3-D) motion analysis $[2,12]$ and othershave demonstrated the effect of treadmill exercise by biomechanical analysis $[13,14]$. However, the effect of conventional PT on gait disturbance as examined by a quantitative biomechanical method remains to be clarified. Moreover, it is unclear whether a single session of PT training has a measurable effect on gait and other standardized measures of function in PD. To this end, the present study evaluated the immediate effects of a single session of PT in PD patients by quantitatively analyzing gait parameters and posture.

\section{Materials and methods Participants}

We recruited the patients with idiopathic PD who were being treated on an out patient basis at our hospital. Between December 2004 and November 2006, 60 participants were recruited. The diagnosis of idiopathic PD was confirmed by a general examination and a neurological examination conducted by trained neurologists according to the UK Brain Bank criteria [15]. Exclusion criteria wereas follows; (1) Patient could notwalk independently without an assistive device such as a cane or walker. (2) Patient had anyother neuromuscular, cardiopulmonary, osteoarticular or psychiatric disorders. (3) Patient with cognitive impairment (Mini-Mental Status Examination score <25). (4) Patient hadmanifested the onoff phenomenon. (5) Patient had participated in PT or any rehabilitation program in the previous 2 weeks. Medication for PD was not modified at least one month prior to the study. The study protocol was approved by the Institutional Review Boardat our hospital (IRB No. 378) and written informed consent was obtained from all participants.

Figure 1 shows the flow of patients through the study. Of the 60 patients invited to participate, 57 agreed to participate (95\%), and 17 excluded due to not meeting inclusion criteria. Forty patients were randomized, 20 allocated to receive PT and 20 to receive no training (control).

\section{Study design}

A single-blind randomized controlled clinical trial design was used to assess the immediate effect of PT. Subjects were randomly allocated to either the PT intervention group or the control group by using computer generated random number sequences. The investigators were unaware of the group allocation.

\section{Intervention}

Participants randomized to the PT intervention group received a single 30-min session of PT. The PT was dministered by licensed, experienced physical therapists. The session included: (1) Stretching exercises (5 min): Exercises mainly targeting the trunk and lower extremities, especially the ankle joint. (2) Strengthening exercises (5 min): Exercises mainly targeting hip flexor and knee extensor muscles. Low intensity (20-30

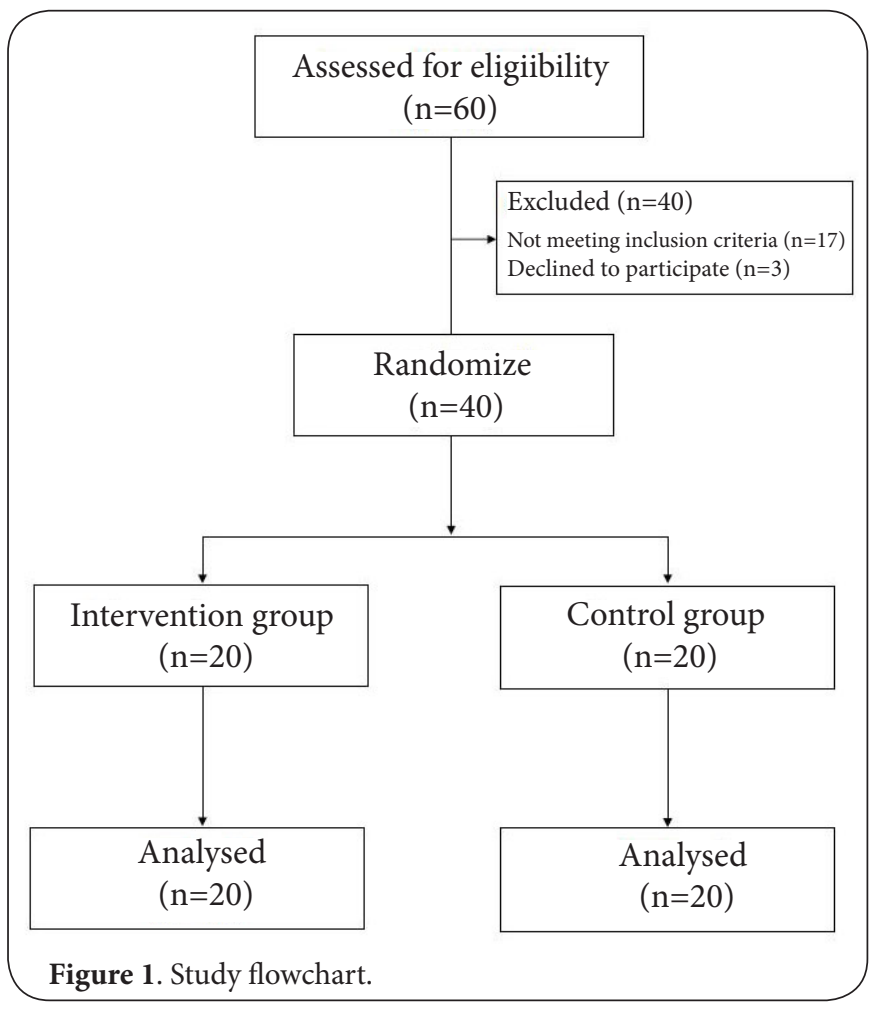

repetitions maximum) isokinetic exercises were chosen. (3) Balance training ( $5 \mathrm{~min}$ ): Maintaining balance on a soft mattress in a standing position. While inthe quadruped position, extending one upper limb together with contralateral lower limb. (4) Recreational game played with a ball (5 min): Playing catch with the therapist using balls of different sizes and weights while sitting and standing. (5) Gait trainingwith external auditory cueing (10 $\mathrm{min})$ : Walking in time to music or a metronome (120 beats per minute).

Participants randomized to the control group rested for $30 \mathrm{~min}$ in a comfortable sitting position and received no therapeutic intervention.

\section{Assessments}

Participants were assessed for disease severity using standard clinical tests, including the Unified Parkinson's disease Rating Scale (UPDRS) and the Hoehn \& Yahr score before the intervention by one physician certified on the UPDRS. Gait assessments were conducted immediately before and immediately after the PT or resting session. Gait data were recorded by a 3-D motion analysis system (Vicon Oxford Metrics, Ltd., Oxford, UK) equipped with 10 cameras which reconstructed the movement trajectories of retro-reflective markers placed on the body at a $60 \mathrm{~Hz}$ sampling rate. Eighteen markers were attached to the following locations on the subject's body: on the top of head, forehead, seventh cervical vertebra, lumbosacral joint and bilateral acromion, elbow, wrist, great trochanter, knee, ankle and fifth metatarsal joint. Subjects were asked to walk 
at a comfortable pace across a 10-m walk way, with data acquired in the 5-m central zone.

The evaluated parameters of gait include: walking speed, step length, cadence, double support duration, single support duration, trunk forward inclination, and range of angular motion of the shoulder, elbow, hip, knee and ankle joints. Step length is defined as the distance between the point of initial contact of one foot and the point of initial contact of the other foot. Cadence is defined asthe number of the steps taken per minute. Double support duration signifies the duration of the double-limb standing balance as a percentage of gait cycle, while single support duration signifies the duration of single-limb standing balance as a percentage of gait cycle. Trunk forward inclination is defined as the trunk angle (C7lumbosacral markers versus sagittal plane). Shoulder angle is defined as the links between the acromion and elbow trochanter markers; elbow angle as the links between the elbow and shoulder-wrist markers; hip angle as the links between the trochanter and acromion-knee markers; knee angle as the links between the knee and trochanter-ankle markers; ankle angle as the links between the ankle and knee-fifth metatarsal joint. Finally, range of angular motion was calculated as the difference between the maximum flexion and extension angles in the gait cycle.

After two rehearsals, the gait parameters were evaluated three times with 1-minute intervals separating the trials, and mean values were used for outcome measures. Data are presented as means and standard deviations (SD).

\section{Statistical analysis}

Differences in the baseline characteristics between the two groups were evaluated by the independent $t$ test for continuous data, the chi-square test for categorical data and the MannWhitney $U$ test for the ordinal variable. A two-way analysis of variance (ANOVA) with repeated measures was used to examine the differences between the groups before and after the session and analyze the interaction between Group and Session in order to quantify the effects of PT. Where a significant interaction existed between Group and Session, a post hoc analysis was performed by drawing an interaction plot. The comparison of step length and range of joint was evaluated for the left and right sides separately. Statistical analysis was performed using the SPSS software package Version 17.0 (SPSS Inc, Chicago, IL).

\section{Results}

All patients completed the intervention (PT or control) session without incident (e.g., no falls, cardiac symptoms or joint problems). Patient baseline characteristics are summarized in Table 1. There were no significant differences between the 2 groups with respect to the measured characteristics.

Gait parameterand range of angular motion of joint results are shown in Table 2. In general, although walking speed and step length were improved after PT intervention, the changes
Table 1. Baseline characteristics of patients.

\begin{tabular}{llll}
\hline & $\begin{array}{l}\text { PT group } \\
(\mathbf{n}=\mathbf{2 0})\end{array}$ & $\begin{array}{l}\text { Control group } \\
(\mathbf{n}=\mathbf{2 0})\end{array}$ & $\boldsymbol{P}$ \\
\hline Gender (M/F) & $10 / 10$ & $11 / 9$ & 0.752 \\
Age (years) & $67.2 \pm 7.9$ & $66.9 \pm 6.3$ & 0.877 \\
Height (cm) & $159.3 \pm 10.2$ & $158.7 \pm 7.9$ & 0.769 \\
Weight (kg) & $55.0 \pm 13.4$ & $56.1 \pm 10.3$ & 0.668 \\
Duration of disease (Y) & $8.7 \pm 6.1$ & $11.4 \pm 5.8$ & 0.166 \\
Hoehn \& Yahr stage & $3.3 \pm 0.5$ & $3.4 \pm 0.5$ & 0.635 \\
\hline UPDRS score & & & \\
\hline Total & $39.4 \pm 17.1$ & $38.4 \pm 13.0$ & 0.882 \\
Mental & $1.4 \pm 1.7$ & $1.8 \pm 1.4$ & 0.221 \\
ADL & $11.1 \pm 6.0$ & $12.5 \pm 7.4$ & 0.529 \\
Motor & $25.1 \pm 10.7$ & $21.1 \pm 7.8$ & 0.414 \\
Complications & $1.9 \pm 2.0$ & $3.0 \pm 3.7$ & 0.512 \\
\hline Medication & & & \\
\hline Levodopa use & $16(80 \%)$ & $17(85 \%)$ & 0.677 \\
Dopa agonist use & $12(60 \%)$ & $16(80 \%)$ & 0.168 \\
Other PD medication & $15(75 \%)$ & $16(80 \%)$ & 0.705 \\
$\begin{array}{l}\text { Mean dose of levodopa } \\
\text { (mg/day) }\end{array}$ & $318(139)$ & $350(153)$ & 0.486 \\
\hline & & & \\
\hline
\end{tabular}

Note: Values are given as mean(SD) unless otherwise indicated ADL: Activities of daily living; PD: Parkinson's disease;

UPDRS: Unified Parkinson Disease Rating Scale

in ROM of joints were $<5$ degrees.

The 2-way ANOVA with repeated measures showed significant improvement in walking speedand amplitude of range of angular motion of the shoulder, elbow and knee joints after PT intervention. There was also asignificant interaction effect for improved walking speed, step length, trunk forward inclination and range of angular motion of all joints between Group and Intervention (Table 3).

Post hoc analysis revealed that walking speed, step length, trunk forward inclination and the range of angular motion of joint differed between the two groups (Figure 2).

\section{Discussion}

This study examined the immediate effects of PT in PD patients by quantitative gait analysis. Although some patients have attempted to exercise by themselves before activities from their experiences, there have been no data to support their theory. To our knowledge, there is only one study to evaluate the immediate effects of PT in PD patients using a 3-D motion analysis system [16]. They reported that the frontal lobe dysfunction prevent the immediate effect of PT in PD by using Frontal Assessment Battery. The dysfunction of programming or working memory might affect the immediate effect of PT.

There are few guidelines for PT in PD that have practical recommendations based on scientific evidence, and the lack of uniform treatment recommendations has hindered research into the efficacy of PT in PD. Keus et al., [17] were able to extract some specific treatment recommendations on the basis 
Wada et al. Physical Therapy and Rehabilitation 2014,

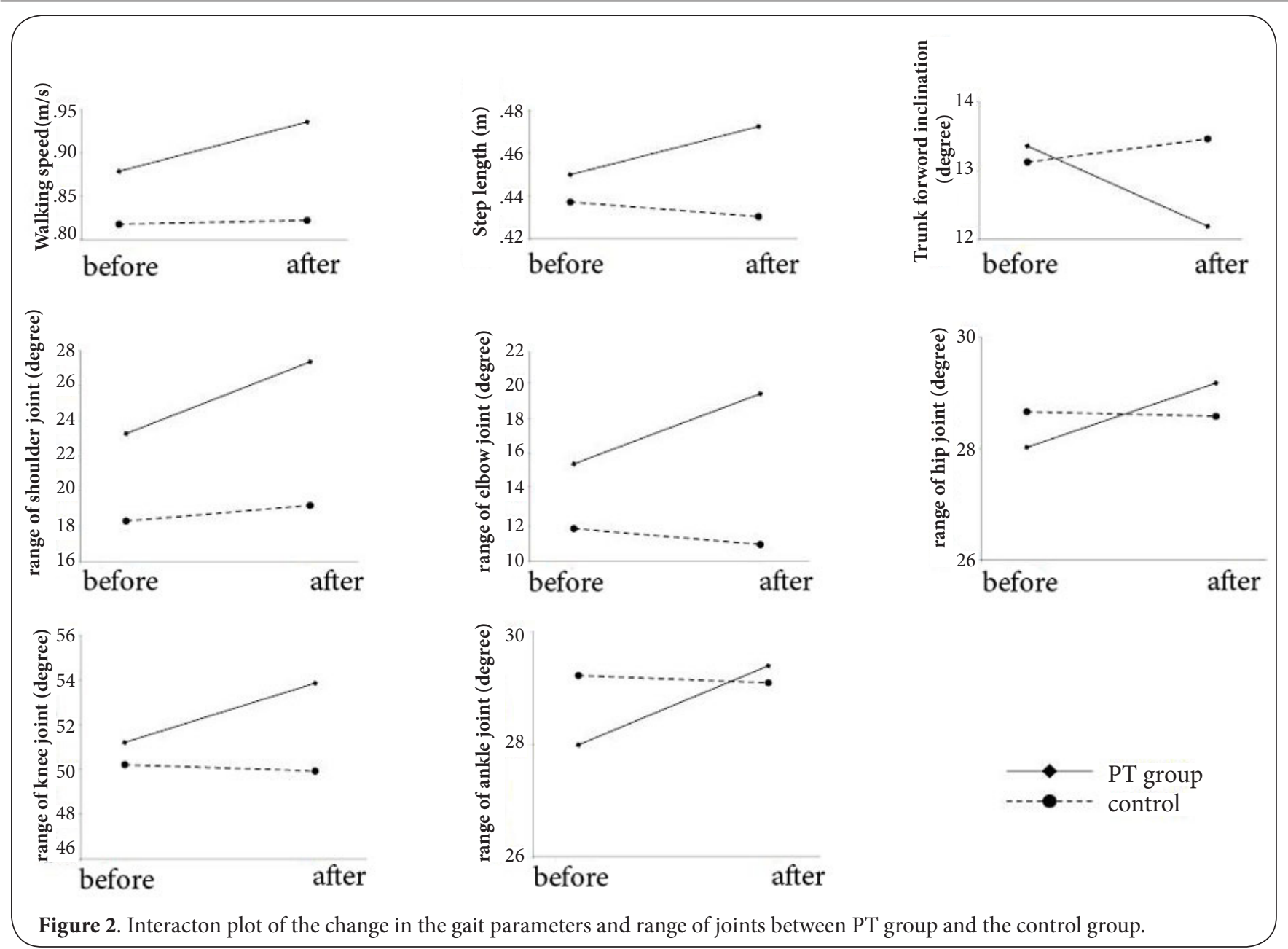

Table 2. Change of gait parameters and range of joints after PT intervention.

\begin{tabular}{lllll}
\hline & \multicolumn{2}{c}{ PT Group } & \multicolumn{2}{c}{ Control } \\
\hline Parameters & \multicolumn{1}{c}{ Before } & \multicolumn{1}{c}{ After } & \multicolumn{1}{c}{ Before } & \multicolumn{1}{c}{ After } \\
\hline Walking speed (m/s) & $0.88 \pm 0.30$ & $0.94 \pm 0.28$ & $0.82 \pm 0.31$ & $0.82 \pm 0.33$ \\
Step length (m) & $0.45 \pm 0.14$ & $0.47 \pm 0.13$ & $0.44 \pm 0.14$ & $0.43 \pm 0.15$ \\
Cadence (step/min) & $114.1 \pm 12.8$ & $116.6 \pm 10.2$ & $111.4 \pm 8.9$ & $112.7 \pm 11.3$ \\
Double support duration (\%) & $25.1 \pm 5.4$ & $24.2 \pm 5.6$ & $28.2 \pm 8.6$ & $26.8 \pm 8.3$ \\
Single support duration (\%) & $37.4 \pm 3.0$ & $37.6 \pm 3.5$ & $36.6 \pm 5.2$ & $36.3 \pm 4.8$ \\
Trunk forward inclination (degrees) & $13.4 \pm 9.9$ & $12.2 \pm 11.2$ & $13.0 \pm 9.5$ & $13.4 \pm 9.6$ \\
Shoulder Flx/Ext range (degrees) & $23.3 \pm 13.9$ & $27.3 \pm 13.2$ & $18.4 \pm 16.1$ & $19.3 \pm 17.4$ \\
Elbow Flx/Ext range (degrees) & $15.6 \pm 10.4$ & $19.6 \pm 11.0$ & $11.9 \pm 8.5$ & $11.0 \pm 8.0$ \\
Hip Flx/Ext range (degrees) & $28.1 \pm 7.8$ & $29.2 \pm 7.7$ & $28.7 \pm 8.6$ & $28.6 \pm 8.8$ \\
Knee Flx/Ext range (degrees) & $51.2 \pm 9.3$ & $53.9 \pm 8.3$ & $50.2 \pm 12.8$ & $49.9 \pm 12.6$ \\
Ankle Dor/Pln range (degrees) & $28.0 \pm 7.7$ & $29.5 \pm 8.3$ & $29.4 \pm 10.7$ & $29.2 \pm 9.9$ \\
\hline
\end{tabular}

Flx: flexion; Ext: extension; Dor: dorsal fexion; Pln: plantar flexion

of evidence from controlled trials: cueing strategies to improve gait and training of joint mobility and muscle power to improve physical capacity. In our study, we decided to use treatment recommendations in our PT session that were supported 
Wada et al. Physical Therapy and Rehabilitation 2014,

http://www.hoajonline.com/journals/pdf/2055-2386-1-5.pdf

Table 3. Results of two-way ANOVA for gait parameters and range of joints.

\begin{tabular}{lllllll}
\hline & \multicolumn{2}{l}{$\begin{array}{l}\text { Group } \\
\text { (PT vs control) }\end{array}$} & \multicolumn{2}{l}{$\begin{array}{l}\text { Intervention } \\
\text { (before vs after) }\end{array}$} & \multicolumn{2}{l}{$\begin{array}{l}\text { Interaction } \\
\text { (Group } \times \text { Intervention) }\end{array}$} \\
\hline Parameter & F & $\boldsymbol{P}$ & F & $\boldsymbol{P}$ & F & \multicolumn{1}{c}{$\boldsymbol{P}$} \\
\hline Walking speed (m/s) & 0.821 & 0.371 & 6.089 & $0.018^{*}$ & 4.545 & $0.040^{*}$ \\
Step length (m) & 0.755 & 0.388 & 3.768 & 0.056 & 12.823 & $0.001^{*}$ \\
Cadence (step/min) & 0.996 & 0.325 & 3.258 & 0.079 & 0.333 & 0.567 \\
Double support duration (\%) & 1.701 & 0.200 & 3.513 & 0.069 & 0.200 & 0.657 \\
Single support duration (\%) & 0.661 & 0.421 & 0.009 & 0.923 & 0.353 & 0.556 \\
Trunk forward inclination (degrees) & 0.053 & 0.818 & 1.458 & 0.231 & 4.883 & $0.030^{*}$ \\
Shoulder Flx/Ext range (degrees) & 3.709 & 0.058 & 23.428 & $<0.001^{*}$ & 9.721 & $0.003^{*}$ \\
Elbow Flx/Ext range (degrees) & 8.863 & $0.004^{*}$ & 10.223 & $0.002^{*}$ & 25.920 & $<0.001^{*}$ \\
Hip Flx/Ext range (degrees) & 0.000 & 0.989 & 3.083 & 0.083 & 4.114 & $0.046^{*}$ \\
Knee Flx/Ext range (degrees) & 1.033 & 0.313 & 15.647 & $<0.001^{*}$ & 24.574 & $<0.001^{*}$ \\
Ankle Dor/Pln range (degrees) & 0.070 & 0.792 & 3.142 & 0.080 & 4.439 & $0.038^{*}$ \\
\hline
\end{tabular}

by evidence obtained from more than two controlled trials. Our PT session consisted of stretching exercises, strengthening exercises, balance training, a recreational game and gait training with external auditory cueing. The exercises aimed at improving range of angular motion, with the stret-ching exercises designed to improve ADL function [18]. We especially focused on training movements of the trunk and ankle joint, which are frequently disordered in PD. Previously, a strength training and high-intensity resistance training program was found to increase muscle power in PD patients $[19,20]$. Moreover, dose-dependent benefits of exercise were suggested to normalize corticomotor excitability in early PD [21]. We therefore trained trunk muscles and hip flexor muscles mainly aiming to stabilize posture and improve step length. Balance training has been found to be effective in improving balance in PD patients $[22,23]$, and in this study we used balance training with proprioceptive feedback. In terms of the recreational training component of our session, patients engaged in a ball-catching exercise since it has been demonstrated that PD patients move as fast as healthy subjects when reaching for a moving or stationary ball under temporal constraints [24].

Gait in PD patients is reported to be improved by the use of visual or auditory cues [25], although it is not clear exactly how such cues improve gait. Perhaps they provide an external rhythm that can compensate for the improperly supplied internal rhythm of the basal ganglia or correct the motor set deficiency in PD. Hackney et al., reported the positive effects of dance for patients with PD [26], where the effects were derived from the musical cue and rhythmical steps. We therefore used auditory cues with rhythmic music at a tempo of 120 beats per minute in our PT session.

The improvement in walking speed among our subjects did not result from an improvement in cadence but rather an increase in step length. This finding may not be unexpected, however, since cadence control is reported to be intact in PD
[8]. Instead, our results revealed significant improvements in step length as well as in range of the joints and posture.

Several studies have investigated the effect of PT using assessment batteries such as the UPDRS or Functional Independence Measure (FIM) $[\mathbf{2 7}, \mathbf{2 8}]$. We assessed the effect of PT using a quantitative biomechanical method. PT training was clearly shown to improve joint excursion in not only the lower extremities but also the upper extremities. The improvement in range of motion of the shoulder suggested that restricted arm swing, which is common in PD, was improved by the PT session. Increased range of motion of the lower extremities can contribute to prolonged step length, and some studies mentioning range of motion of the lower extremities in PD $[4,5,12]$ report that improvement in arm swing influences improvement in balance and appearance of the gait.

Walking performance in patients with PD is variable. Although Urquhart et al., [29] demonstrated that measures of gait speed, cadence, step length and double support duration were highly consistent over a 7-day period, in the present study we collected gait data immediately before and immediately after intervention in order to minimize the variation from the onoff phenomenon.

Some limitations of this study should be noted. First, the number of subjects was small, which limits the generalization of the results. Second, the reliability (repeatability) of the computerized 3D system has not been investigated for PD patients, but the test-retest reliability of the system has been described for stroke patients [30]. In addition, the duration of the positive effects of PT under taken in this study were not evaluated. Herman et al., [31] reported the effects of tread mill training were retained 4 weeks later and Miyai et al., [14] demonstrated that the effects of body weight-supported treadmill training on short-step gait in PD lasted for 1 month. Further studies should include a sufficient number of participants who should be followed over the longerterm. 
Wada et al. Physical Therapy and Rehabilitation 2014,

http://www.hoajonline.com/journals/pdf/2055-2386-1-5.pdf

doi: $10.7243 / 2055-2386-1-5$

\section{Conclusion}

The results demonstrate thata single PT session can confer immediate positive effects on gait parameters. PT might improve not only gait parameters, but also posture and range of joints. Single session of PT programs can therefore be expected to prevent falls if carried out before going out.

\section{Competing interests}

The authors declare that they have no competing interests.

Authors' contributions

\begin{tabular}{|l|c|c|c|c|c|c|}
\hline Authors' contributions & NW & MS & MT & YI & KO & KS \\
\hline Research concept and design & $\checkmark$ & -- & -- & -- & -- & -- \\
\hline Collection and/or assembly of data & -- & $\checkmark$ & $\checkmark$ & $\checkmark$ & -- & -- \\
\hline Data analysis and interpretation & $\checkmark$ & -- & -- & -- & -- & -- \\
\hline Writing the article & $\checkmark$ & -- & -- & -- & -- & -- \\
\hline Critical revision of the article & -- & -- & -- & -- & $\checkmark$ & $\checkmark$ \\
\hline Final approval of article & $\checkmark$ & -- & -- & -- & -- & -- \\
\hline Statistical analysis & $\checkmark$ & -- & -- & -- & -- & -- \\
\hline
\end{tabular}

\section{Acknowledgement}

This study was supported by a Grant-in-Aid for Scientific Research (No. 18700454, to N.H.) from the Japanese Ministry of Education, Culture, Sports, Science and Technology.

\section{Publication history}

Editor: Giorgio Ferriero, Institute of Care and Research, Italy. Received: 30-Jul-2014 Final Revised: 25-Aug-2014

Accepted: 29-Aug-2014 Published: 11-Sep-2014

\section{References}

1. Sofuwa O, Nieuwboer A, Desloovere K, Willems AM, Chavret F and Jonkers I. Quantitative gait analysis in Parkinson's disease: comparison with a healthy control group. Arch Phys Med Rehabil. 2005; 86:1007-13. | Article | PubMed

2. Morris M, lansek R, McGinley J, Matyas T and Huxham F. Threedimensional gait biomechanics in Parkinson's disease: evidence for a centrally mediated amplitude regulation disorder. Mov Disord. 2005; 20:40-50. | Article | PubMed

3. Blin O, Ferrandez AM and Serratrice G. Quantitative analysis of gait in Parkinson patients: increased variability of stride length. J Neurol Sci. 1990; 98:91-7. | Article | PubMed

4. Morris ME, lansek R, Matyas TA and Summers JJ. Stride length regulation in Parkinson's disease. Normalization strategies and underlying mechanisms. Brain. 1996; 119 ( Pt 2):551-68. I Article I PubMed

5. Pickering RM, Grimbergen YA, Rigney U, Ashburn A, Mazibrada G, Wood $B$, Gray P, Kerr G and Bloem BR. A meta-analysis of six prospective studies of falling in Parkinson's disease. Mov Disord. 2007; 22:1892-900. | Article | PubMed

6. Bloem BR, Grimbergen YA, Cramer M, Willemsen M and Zwinderman AH Prospective assessment of falls in Parkinson's disease. J Neurol. 2001; 248:950-8. | Article | PubMed

7. Hausdorff JM, Schaafsma JD, Balash Y, Bartels AL, Gurevich T and Giladi N. Impaired regulation of stride variability in Parkinson's disease subjects with freezing of gait. Exp Brain Res. 2003; 149:187-94. | PubMed

8. Schaafsma JD, Giladi N, Balash Y, Bartels AL, Gurevich T and Hausdorff JM. Gait dynamics in Parkinson's disease: relationship to Parkinsonian features, falls and response to levodopa. J Neurol Sci. 2003; 212:47-53. | Article | PubMed
9. Keus SH, Munneke M, Nijkrake MJ, Kwakkel G and Bloem BR. Physical therapy in Parkinson's disease: evolution and future challenges. Mov Disord. 2009; 24:1-14. | Article | PubMed

10. Morris ME, Martin CL and Schenkman ML. Striding out with Parkinson disease: evidence-based physical therapy for gait disorders. Phys Ther 2010; 90:280-8. | Article | PubMed Abstract | PubMed Full Text

11. De Goede CJ, Keus SH, Kwakkel G and Wagenaar RC. The effects of physical therapy in Parkinson's disease: a research synthesis. Arch Phys Med Rehabil. 2001; 82:509-15. | Article | PubMed

12. Ferrarin M, Lopiano L, Rizzone M, Lanotte M, Bergamasco B, Recalcati $M$ and Pedotti A. Quantitative analysis of gait in Parkinson's disease: a pilot study on the effects of bilateral sub-thalamic stimulation. Gait Posture. 2002; 16:135-48. | Article | PubMed

13. Frenkel-Toledo S, Giladi N, Peretz C, Herman T, Gruendlinger L and Hausdorff JM. Treadmill walking as an external pacemaker to improve gait rhythm and stability in Parkinson's disease. Mov Disord. 2005. 20:1109-14. | Article | PubMed

14. Miyai I, Fujimoto $Y$, Yamamoto $H$, Ueda Y, Saito T, Nozaki S and Kang J. Long-term effect of body weight-supported treadmill training in Parkinson's disease: a randomized controlled trial. Arch Phys Med Rehabil. 2002; 83:1370-3. | Article | PubMed

15. Hughes AJ, Daniel SE, Kilford L and Lees AJ. Accuracy of clinical diagnosis of idiopathic Parkinson's disease: a clinico-pathological study of $\mathbf{1 0 0}$ cases. J Neurol Neurosurg Psychiatry. 1992; 55:181-4. I Article I PubMed Abstract | PubMed Full Text

16. Sohmiya M, Wada N, Tazawa M, Okamoto K and Shirakura K. Immediate effects of physical therapy on gait disturbance and frontal assessment battery in Parkinson's disease. Geriatr Gerontol Int. 2013; 13:630-7. | Article | PubMed

17. Keus SH, Bloem BR, Hendriks EJ, Bredero-Cohen AB and Munneke M. Evidence-based analysis of physical therapy in Parkinson's disease with recommendations for practice and research. Mov Disord. 2007; 22:45160. | Article | PubMed

18. Formisano R, Pratesi L, Modarelli FT, Bonifati V and Meco G Rehabilitation and Parkinson's disease. Scand J Rehabil Med. 1992 24:157-60. | Article | PubMed

19. Corcos DM, Robichaud JA, David FJ, Leurgans SE, Vaillancourt DE, Poon C, Rafferty MR, Kohrt WM and Comella CL. A two-year randomized controlled trial of progressive resistance exercise for Parkinson's disease. Mov Disord. 2013; 28:1230-40. | Article | PubMed Abstract | PubMed Full Text

20. Falvo MJ, Schilling BK and Earhart GM. Parkinson's disease and resistive exercise: rationale, review, and recommendations. Mov Disord. 2008; 23:1-11. | Article | PubMed

21. Fisher BE, Wu AD, Salem GJ, Song J, Lin CH, Yip J, Cen S, Gordon J, Jakowec $M$ and Petzinger $G$. The effect of exercise training in improving motor performance and corticomotor excitability in people with early Parkinson's disease. Arch Phys Med Rehabil. 2008; 89:1221-9. | Article | PubMed Abstract | PubMed Full Text

22. Hirsch MA, Toole T, Maitland CG and Rider RA. The effects of balance training and high-intensity resistance training on persons with idiopathic Parkinson's disease. Arch Phys Med Rehabil. 2003; 84:110917. | Article | PubMed

23. Toole T, Hirsch MA, Forkink A, Lehman DA and Maitland CG. The effects of a balance and strength training program on equilibrium in Parkinsonism: A preliminary study. NeuroRehabilitation. 2000; 14:165174. | Article | PubMed

24. Majsak MJ, Kaminski T, Gentile AM and Gordon AM. Effects of a moving target versus a temporal constraint on reach and grasp in patients with Parkinson's disease. Exp Neurol. 2008; 210:479-88. | Article | PubMed

25. Nieuwboer A, Kwakkel G, Rochester L, Jones D, van Wegen E, Willems AM, Chavret F, Hetherington V, Baker $K$ and Lim I. Cueing training in the home improves gait-related mobility in Parkinson's disease: the RESCUE trial. J Neurol Neurosurg Psychiatry. 2007; 78:134-40. | Article | PubMed Abstract | PubMed Full Text 
Wada et al. Physical Therapy and Rehabilitation 2014,

http://www.hoajonline.com/journals/pdf/2055-2386-1-5.pdf

26. Hackney ME and Earhart GM. Effects of dance on movement control in Parkinson's disease: a comparison of Argentine tango and American ballroom. J Rehabil Med. 2009; 41:475-81. | Article | PubMed Abstract | PubMed Full Text

27. Comella CL, Stebbins GT, Brown-Toms N and Goetz CG. Physical therapy and Parkinson's disease: a controlled clinical trial. Neurology. 1994; 44:376-8. | Article | PubMed

28. Ellis T, de Goede CJ, Feldman RG, Wolters EC, Kwakkel G and Wagenaar RC. Efficacy of a physical therapy program in patients with Parkinson's disease: a randomized controlled trial. Arch Phys Med Rehabil. 2005; 86:626-32. | Article | PubMed

29. Urquhart DM, Morris ME and lansek R. Gait consistency over a 7-day interval in people with Parkinson's disease. Arch Phys Med Rehabil. 1999; 80:696-701. | Article | PubMed

30. Yavuzer G, Oken O, Elhan A and Stam HJ. Repeatability of lower limb three-dimensional kinematics in patients with stroke. Gait Posture. 2008; 27:31-5. | Article I PubMed

31. Herman T, Giladi N, Gruendlinger L and Hausdorff JM. Six weeks of intensive treadmill training improves gait and quality of life in patients with Parkinson's disease: a pilot study. Arch Phys Med Rehabil. 2007; 88:1154-8. | Article | PubMed

\section{Citation:}

Wada N, Sohmiya M, Tazawa M, Ibe Y, Okamoto K and Shirakura K. Immediate positive effects of physical therapy on gait disturbance in patients with parkinson's disease. Phys Ther Rehabil. 2014; 1:5. http://dx.doi.org/10.7243/2055-2386-1-5 